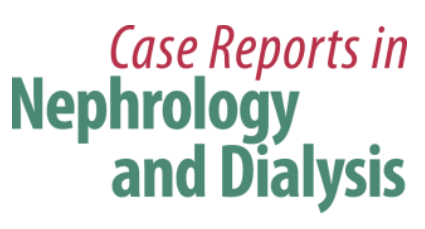

\title{
Nephrotic Syndrome Complicated with Deep Venous Thrombosis in the Upper Extremities
}

\author{
Akira Onishi $^{\mathrm{a}}$ Makoto Inoue $^{\mathrm{a}}$ Toshimi Imai $^{\mathrm{a}}$ Shin-ichi Takeda ${ }^{\mathrm{a}}$ \\ Mariko Kondo $^{b}$ Kazuyuki Shimada ${ }^{b}$ Daisuke Nagata $^{a}$ \\ ${ }^{a}$ Division of Nephrology, Department of Medicine, Jichi Medical University, Shimotsuke \\ City, and ${ }^{\text {b}}$ Shin-Oyama City Hospital, Oyama, Japan
}

\section{Key Words}

Nephrotic syndrome $\cdot$ Membranous nephropathy $\cdot$ Upper-extremity deep venous thrombosis

\begin{abstract}
Deep venous thrombosis (DVT) in the upper extremities is a rare but important clinical illness, which leads to severe complications such as pulmonary embolism. Unlike DVT in the lower extremities, which is mainly induced by a hypercoagulable state, DVT in the upper extremities is usually caused by mechanical obstruction or anatomical stenosis in the venous system. We herein report a case in which DVT developed in the left upper limb during treatment of nephrotic syndrome. This is the first case report of upper-extremity DVT in association with nephrotic syndrome in the literature. Our patient was a 56-year-old male with nephrotic syndrome due to idiopathic membranous nephropathy who was treated with $40 \mathrm{mg} /$ day of prednisolone. During corticosteroid therapy, he developed a swelling of the left upper limb. Computed tomography revealed thrombi in the left internal jugular vein and the left subclavian vein without anatomical abnormalities in his venous system. Thus, he was diagnosed with DVT of the upper extremities. After the initiation of warfarin treatment and subsequent regression of nephrotic syndrome, the swelling disappeared and the thrombi significantly diminished. DVT should be considered when upper-extremity edema is observed in patients with nephrotic syndrome.

(c) 2014 S. Karger AG, Basel
\end{abstract}

\section{Introduction}

Deep venous thrombosis (DVT) is a complication well-known to be associated with nephrotic syndrome. In patients with nephrotic syndrome, DVT is reported to be observed 


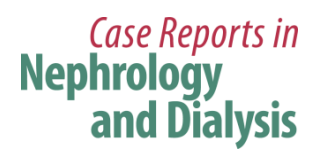

\begin{tabular}{l|l}
\hline Case Rep Nephrol Dial 2015;5:1-5 \\
\hline DOI: $10.1159 / 000365567$ & $\begin{array}{l}\text { C 2014 S. Karger AG, Basel } \\
\text { www.karger.com/cnd }\end{array}$ \\
\hline
\end{tabular}

Onishi et al.: Nephrotic Syndrome Complicated with Deep Venous Thrombosis in the Upper Extremities

mostly in the lower extremities, renal veins, and pulmonary arteries [1-3]. However, there are no reports of DVT developing in the upper extremities of patients with nephrotic syndrome. We herein report a case in which DVT developed in the left arm during treatment of nephrotic syndrome due to idiopathic membranous nephropathy.

\section{Case Report}

A 56-year-old male was admitted to our hospital in May 2012 for evaluation of nephrotic syndrome. He had neither a personal nor family history of notable illness such as thrombotic diseases. One month previously, he had presented with bilateral leg edema. Two weeks before admission, he had been diagnosed with massive proteinuria with hypoalbuminemia in another clinic. His weight had increased by approximately $8 \mathrm{~kg}$ in 1 month.

Physical examination on admission revealed the following: height $168 \mathrm{~cm}$, weight 61.6 $\mathrm{kg}$, blood pressure $124 / 75 \mathrm{~mm} \mathrm{Hg}$, pulse rate 80 beats/min with a regular rhythm, and temperature $36.4^{\circ} \mathrm{C}$. The lungs were clear and heart sounds were normal. Massive symmetrical leg edema was observed. There was no rash, lymphadenopathy, or joint swelling. The rest of the physical examination was unremarkable.

Urine sediment analysis revealed 5-9 red blood cells per high power field. Urinary protein excretion was $11.8 \mathrm{~g} / 24 \mathrm{~h}$. Blood analysis, biochemical and serological examination showed a white blood cell count of $7.7 \times 10^{3} / \mu \mathrm{l}$, hemoglobin $15.4 \mathrm{~g} / \mathrm{dl}$, platelet count $315 \times$ $10^{3} / \mu \mathrm{l}$, total protein $3.7 \mathrm{~g} / \mathrm{dl}$, albumin $0.8 \mathrm{~g} / \mathrm{dl}$, urea nitrogen $15 \mathrm{mg} / \mathrm{dl}$, creatinine 0.96 $\mathrm{mg} / \mathrm{dl}$, uric acid $5.8 \mathrm{mg} / \mathrm{dl}$, total cholesterol $460 \mathrm{mg} / \mathrm{dl}$, hemoglobin A1c 5.7\%, IgG 213 $\mathrm{mg} / \mathrm{dl}$, IgA $320 \mathrm{mg} / \mathrm{dl}$, and IgM $57 \mathrm{mg} / \mathrm{dl}$. Serum electrophoresis revealed no monoclonal peak. The third and fourth components of complement were within the normal limits. Antinuclear antibody, rheumatoid factor activity, hepatitis B and C, and human immunodeficiency virus were all negative. There was a marked elevation in fibrinogen $(658.9 \mathrm{mg} / \mathrm{dl})$ and d-dimer $(3.1 \mu \mathrm{g} / \mathrm{ml})$, and a decrease in antithrombin III activity (66.3\%). Prothrombin time, prothrombin time-international normalized ratio, and activated partial thromboplastin time were all normal. A fecal occult blood test, computed tomography (CT) through the chest and abdomen, and upper endoscopy did not suggest the presence of malignancy.

Because our patient initially refused renal biopsy, he was empirically treated with 40 $\mathrm{mg} /$ day of prednisolone from the third day after admission, together with continuous intravenous infusion of heparin for prophylaxis of thrombotic complications. However, he presented no clinical improvement and then received a percutaneous renal biopsy on day 34. The specimen consisted of 18 glomeruli showing diffuse and irregular thickening of the glomerular basement membrane with deposition of IgG4, compatible to idiopathic membranous nephropathy stage II. During prednisolone treatment, he developed a gradually progressive swelling of the upper and lower left arm. Levofloxacin was administrated because phlegmon in the upper extremity was considered, but the swelling worsened. Contrast-enhanced CT on day 54 showed obstructions of the left internal jugular vein and the left subclavian vein by large thrombi (fig. 1a, b). No anatomical abnormality in the venous system was observed. The blood levels of protein $C$, protein $S$, and $\beta_{2}$-glycoprotein I were within the normal ranges. In addition to the heparin infusion, oral warfarin was added, with prothrombin time-international normalized ratio monitoring between 2 and 3. Edema of the patient's left upper limbs gradually improved and disappeared within 1 month. After his discharge on day 98, the edema completely disappeared. A contrast CT 89 days after discharge confirmed a significant reduction of thrombi (fig. 1c, d). After the administration of 


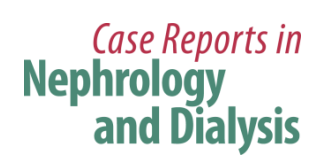

\begin{tabular}{l|l}
\hline Case Rep Nephrol Dial 2015;5:1-5 \\
\hline DOI: $10.1159 / 000365567$ & $\begin{array}{l}\text { C 2014 S. Karger AG, Basel } \\
\text { www.karger.com/cnd }\end{array}$ \\
\hline
\end{tabular}

Onishi et al.: Nephrotic Syndrome Complicated with Deep Venous Thrombosis in the Upper Extremities

cyclosporine, his nephrotic syndrome was in remission, and no further thrombotic symptoms have been seen to date.

\section{Discussion}

Thromboembolism occurs in approximately $25 \%$ of adult patients with nephrotic syndrome [4]. The major types of thrombotic complications in nephrotic syndrome cases are DVT, pulmonary embolism, and renal vein thrombosis [1, 3]. Sometimes the inferior vena cava, and, rarely, the portal, splenic, and superior mesenteric vein can be affected $[2,5,6]$. Additionally, a pediatric case of nephrotic syndrome exhibiting thrombosis of the internal jugular vein accompanied by neck pain has been reported [7]. However, there have been no reports of adult nephrotic cases with thrombosis of the internal jugular vein or of nephrotic cases with thrombosis of the subclavian vein.

Upper-extremity DVT is a rarer manifestation of venous thromboembolic disease than that in the lower extremities [8]. In recent years, that manifestation has become more commonly recognized because of the increased use of central venous catheters, artificial heart pacemakers, and defibrillators [8]. Mechanical stenosis and venous obstruction by those devices, pulmonary cancer, or thoracic outlet syndrome induce the formation of thrombi in the brachial, axillary, subclavian, and internal jugular vein, or the superior vena cava, resulting in DVT in the upper extremities $[8,9]$. Furthermore, left innominate vein stenosis due to extrinsic compression by the sternum and arch vessels can cause venous stasis in the upper extremities [10]. Secondary pathogenesis by mechanical stenosis and venous obstruction described above is associated with more than $80 \%$ of the cases with upper-extremity DVT. The rest, which accounts for less than $20 \%$ of the cases, is caused by arm exercise or idiopathic conditions [8]. In our case, there were no clinical symptoms or imaging findings suggestive of structural abnormalities in the venous system of the upper extremities or the neck. In addition, there was no episode of arm exercise during the hospitalization. In adult cases of nephrotic syndrome, most of the venous thromboses occur within 6 months after the diagnosis of nephrotic syndrome, especially in association with the increase of urinary protein and decrease of serum albumin [11]. In the present case, DVT occurred approximately 2 months after the diagnosis of nephrotic syndrome when marked proteinuria and hypoalbuminemia had persisted because of poor effects of corticosteroid therapy. In addition, DVT in our case improved alongside the improvement of the nephrotic syndrome after the administration of cyclosporine. Therefore, we believe that the most probable cause of upper-extremity DVT in this case was associated with nephrotic syndrome, which is hardly ever the case, as described above [9]. Furthermore, the 2-month duration of oral corticosteroid therapy, which is also an important factor for venous thrombosis, presumably had some influence on DVT in this case [12]. We consider that rest during hospitalization, especially after renal biopsy, also might have advanced the likelihood of thrombosis [13].

The first-line therapy of upper-extremity DVT is anticoagulation by heparin or warfarin when DVT involves the axillary or more proximal veins [14]. In the present case, the swelling of the upper limb was successfully improved along with a reduction of thrombus size after the administration of warfarin and heparin without causing pulmonary embolism, which is a life-threatening complication of upper-extremity DVT [15]. In addition to the effectiveness of anticoagulation therapy, the remission of nephrotic syndrome and the tapering of prednisolone might have contributed to the improvement of upper-extremity DVT by reducing the thrombophilic state. 
Onishi et al.: Nephrotic Syndrome Complicated with Deep Venous Thrombosis in the Upper Extremities

In conclusion, to the best of our knowledge, this is the first case report of upperextremity DVT associated with nephrotic syndrome. It is necessary to consider upperextremity DVT when upper-extremity edema is observed in patients with nephrotic syndrome. The detailed mechanisms of upper-extremity DVT in association with nephrotic syndrome need to be elucidated.

\section{Acknowledgement}

Gary Baley was the academic editor of the manuscript.

\section{Disclosure Statement}

All authors report no conflicts of interest.

\section{References}

1 Li SJ, Guo JZ, Zuo K, Zhang J, Wu Y, Zhou CS, Lu GM, Liu ZH: Thromboembolic complications in membranous nephropathy patients with nephrotic syndrome - a prospective study. Thromb Res 2012;130:501-505.

-2 Lilova MI, Velkovski IG, Topalov IB: Thromboembolic complications in children with nephrotic syndrome in Bulgaria (1974-1996). Pediatr Nephrol 2000;15:74-78.

-3 Ambler B, Irvine S, Selvarajah V, Isles C: Nephrotic syndrome presenting as deep vein thrombosis or pulmonary embolism. Emerg Med J 2008;25:241-242.

-4 Kerlin BA, Ayoob R, Smoyer WE: Epidemiology and pathophysiology of nephrotic syndrome-associated thromboembolic disease. Clin J Am Soc Nephrol 2012;7:513-520.

-5 Prabahar MR, Jayakumar M, Soundararajan P: Chronic inferior venacava thrombosis in membranous nephropathy. Nephrol Dial Transplant 2008;23:2422-2423.

6 Wang J, Fan Q, Chen Y, Dong X, Zhang Y, Feng J, Ma J, Wang L: A case report of minimal change nephrotic syndrome complicated with portal, splenic and superior mesenteric vein thrombosis. Clin Nephrol 2012;77:505-509.

-7 Vyas V, Kapoor S, Panda M, Mandal Ravi RN: Thrombosis of internal jugular vein in nephrotic syndrome presenting as neck pain. Indian J Pediatr 2012;79:1388.

-8 Kucher N: Clinical practice. Deep-vein thrombosis of the upper extremities. N Engl J Med 2011;364:861869.

-9 Joffe HV, Kucher N, Tapson VF, Goldhaber SZ: Upper-extremity deep vein thrombosis: a prospective registry of 592 patients. Circulation 2004;110:1605-1611.

-10 Kotoda A, Akimoto T, Kato M, Kanazawa H, Nakata M, Sugase T, Ogura M, Ito C, Sugimoto H, Muto S, Kusano E: Central venous stenosis among hemodialysis patients is often not associated with previous central venous catheters. ASAIO J 2011;57:439-443.

11 Mahmoodi BK, ten Kate MK, Waanders F, Veeger NJ, Brouwer JL, Vogt L, Navis G, van der Meer J: High absolute risks and predictors of venous and arterial thromboembolic events in patients with nephrotic syndrome: results from a large retrospective cohort study. Circulation 2008;117:224-230.

12 Huerta C, Johansson S, Wallander MA, Garcia Rodriguez LA: Risk factors and short-term mortality of venous thromboembolism diagnosed in the primary care setting in the United Kingdom. Arch Intern Med 2007;167:935-943.

13 Hollyoak M, Woodruff P, Muller M, Daunt N, Weir P: Deep venous thrombosis in postoperative vascular surgical patients: a frequent finding without prophylaxis. J Vasc Surg 2001;34:656-660.

14 Kearon C, Akl EA, Comerota AJ, Prandoni P, Bounameaux H, Goldhaber SZ, Nelson ME, Wells PS, Gould MK, Dentali F, Crowther M, Kahn SR: Antithrombotic therapy for VTE disease: antithrombotic therapy and prevention of thrombosis, 9th ed: American College of Chest Physicians Evidence-Based Clinical Practice Guidelines. Chest 2012;141:e419S-e494S.

15 Hingorani A, Ascher E, Markevich N, Yorkovich W, Schutzer R, Mutyala M, Nahata S, Jacob T: Risk factors for mortality in patients with upper extremity and internal jugular deep venous thrombosis. J Vasc Surg 2005;41:476-478. 
Onishi et al.: Nephrotic Syndrome Complicated with Deep Venous Thrombosis in the Upper Extremities
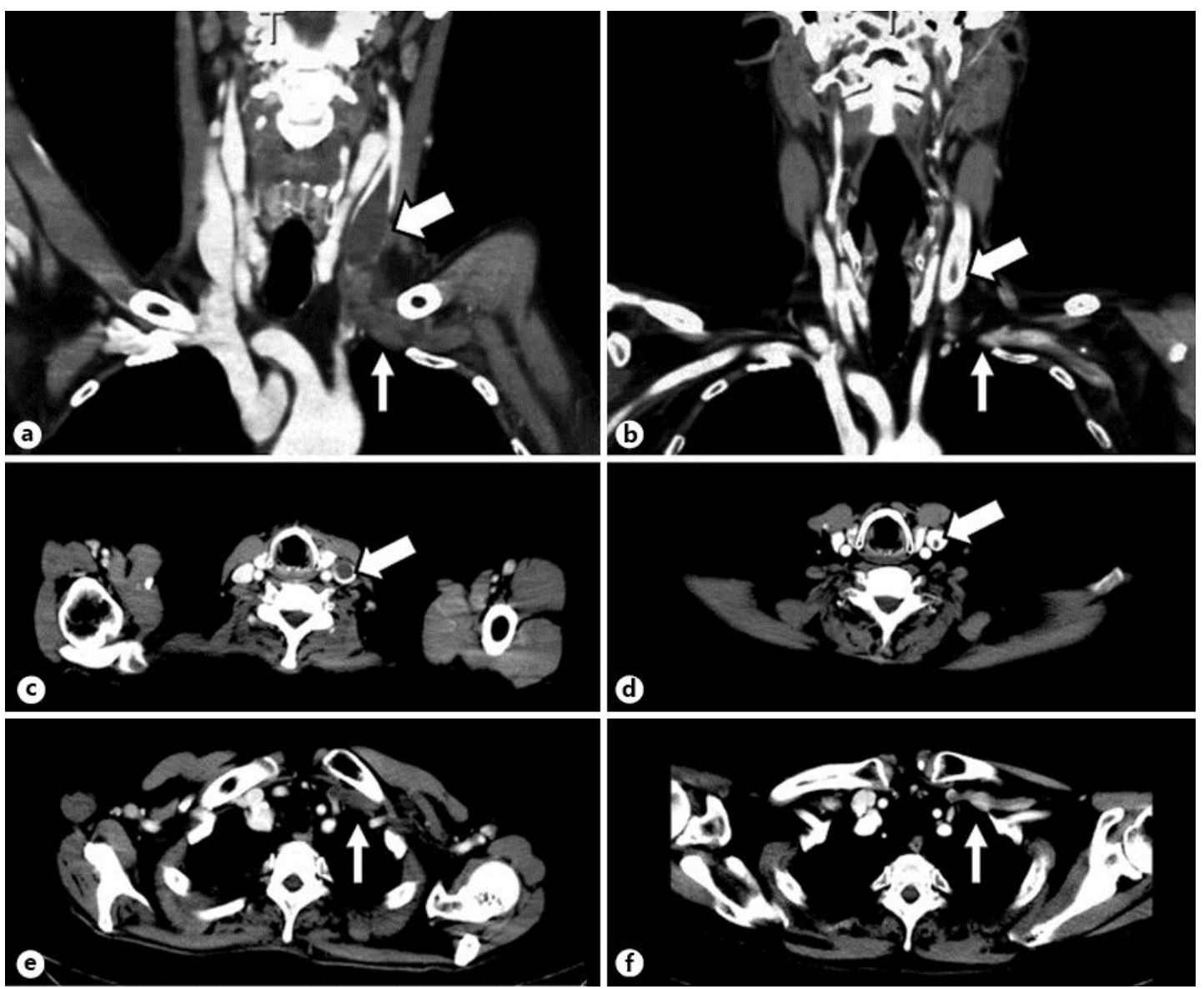

Fig. 1. Contrast-enhanced CT images on the 54th day of hospitalization (a-c) and 89 days after discharge, i.e. 186 days after admission (d-f). Thrombi were observed in the left internal jugular vein (thick arrows) and the left subclavian vein (thin arrows) as gray masses in coronal (a) and axial views (b, c). 132 days later, the thrombi in the left internal jugular vein (thick arrow) had become smaller in size, and those in the left subclavian vein (thin arrows) had disappeared in coronal (d) and axial views (e, f). 